Article

\title{
Preparation and Characterization of a Low-Cost and Natural Material-Based Reticulated Porous Diatomite-Kaolin Composite
}

\author{
Sujin Lee ${ }^{1,2}$, Jang-Hoon Ha ${ }^{1, *}$, Jongman Lee ${ }^{1}$, In-Hyuck Song ${ }^{1}$ and Se-Hun Kwon ${ }^{2, *}$ \\ 1 Powder and Ceramics Division, Korea Institute of Materials Science, 797 Changwondaero, Seongsan-gu, \\ Changwon, Gyeongsangnam-do 51508, Korea; adsj1503@kims.re.kr (S.L.); jmlee@kims.re.kr (J.L.); \\ sih1654@kims.re.kr (I.-H.S.) \\ 2 School of Materials Science and Engineering, Pusan National University, 2 Busandaehak-ro 63beon-gil, \\ Geumjeong-gu, Busan 46241, Korea \\ * Correspondence: hjhoon@kims.re.kr (J.-H.H.); sehun@pusan.ac.kr (S.-H.K.)
}

Received: 29 January 2020; Accepted: 13 March 2020; Published: 20 March 2020

check for updates

\begin{abstract}
In recent years, porous ceramics have been increasingly developed owing to their high levels of high-temperature stability and chemical stability. These properties are far superior to porous polymers and porous metals. As a representative porous ceramic, reticulated porous ceramics have been fabricated for several decades owing to their overwhelmingly high porosity, which is usually above $90 \%$. There are growing concerns about the environmental problems. However, the data on the preparation of low-cost and natural material-based reticulated porous ceramics are not enough. Therefore, the authors studied the preparations and characterizations of reticulated porous ceramics prepared using diatomite and kaolin, and compared them to typical reticulated porous alumina. The obtained data were used to determine whether the reticulated porous diatomite-kaolin composite can be practically used in non-hard loading conditions. The structural properties and dielectric breakdown strength of the reticulated porous ceramics were examined using scanning electron microscopy, mercury porosimetry, $\mu$-computed tomography $(\mathrm{CT})$, and standard test apparatus of dielectric breakdown voltage.
\end{abstract}

Keywords: reticulated porous diatomite; reticulated porous alumina; dielectric breakdown strength; compressive strength

\section{Introduction}

Porous ceramics have been extensively studied [1], because they possess various advantageous properties. Exceptionally high thermal and chemical stability of porous ceramics has secured their position in the market, made their position secure, overwhelming their competitors such as porous polymers and porous metals. Among the various types of porous ceramics, reticulated porous ceramics have well-defined open pore structures, whose porosity is generally above $90 \%$. Therefore, reticulated porous ceramics [2] are prepared using various types of ceramics that are laid in an extreme edge of the advantages of porous ceramics.

However, the inherent low mechanical stability of reticulated porous ceramics which is a disadvantageous legacy of ceramics severely inhibits their application in various fields. The maximum obtainable compressive strengths of reticulated porous ceramics, which it strongly depend on the PPI (pores per inch), are generally low, such as reticulated porous alumina (1.60 MPa) [3], reticulated porous aluminum nitride (1.4 MPa) [4], reticulated silicon nitride (2.67 MPa) [5], reticulated porous silicon carbide $((1.59 \pm 0.13 \mathrm{MPa})[6]$ and $(1.08 \pm 0.17 \mathrm{MPa})[7])$ reticulated porous zirconia $(0.85 \pm 0.13 \mathrm{MPa})[8]$, 
reticulated porous cordierite $(0.47 \pm 0.02 \mathrm{MPa})$ [9], reticulated porous yttrium disilicate (1.28 MPa) [10], and reticulated porous mullite $(0.62 \pm 0.03 \mathrm{MPa})[11]$.

Therefore, there are two possible ways to enlarge the application fields of reticulated porous ceramics: by minimizing the weak point, and maximizing the strong point. To minimize the weak point, several approaches have been investigated to improve the compressive strengths of reticulated porous ceramics. For example, dip-coating [12], whisker-reinforcement coating [5], slurry rheology modification [13], multiple slurry coatings [14], centrifuge coating [15], and vacuum infiltration coating [16], have been introduced to enhance the compressive strengths of reticulated porous ceramics. The authors also previously reported that the compressive strength of the reticulated porous alumina can be improved by increasing the sintering temperature and/or number of alumina coating layers [17].

However, in this study, the authors attempted to maximize the strong point of reticulated porous ceramics, such as low cost, low density, and high permeability. Generally, if the PPI of reticulated porous ceramic approaches the value of 10 , the preparation is easy. However, it is difficult to handle and use them practically owing to the high fragility, inevitably induced by the combination of high porosity, large pore size, insufficient number of strut walls, and inherent brittleness of ceramics. In contrast, if the PPI of reticulated porous ceramic approaches the value of 60 , the preparation is difficult because completely coating the internal pores with ceramic slurry is difficult. It is also very difficult to remove the excess ceramic slurry and enable the formation of a thin ceramic coating over the struts of the sacrificial polymer template [1]. Consequentially several blocked inter-connected pores are formed, generated by the remnants of ceramic slurry, which should have been removed but remained after the squeezing process, this can severely degrade the two main advantages of reticulated porous ceramics: low density and high permeability.

Hence, the authors introduced diatomite as a feasible candidate for reticulated porous ceramic innovatively because diatomite is an inherently porous and irregular natural low-cost material. Detailed descriptions and basic properties of diatomite have been comprehensively explained in previous reports [18-30]. Recently, the authors reported several types of porous diatomite such as (1) uniaxially-pressed diatomite-based support layers for microfiltration [18-27], (2) extruded diatomite-based support layers for microfiltration [28,29], and (3) particle-stabilized diatomite foam with a bimodal pore structure [30]. However, to the best of author's knowledge, there are no studies on the preparation and characterizations of reticulated porous diatomite-kaolin composite.

Generally, the success and failure of the fabrication of conventional reticulated porous ceramics strongly depend on to the resemblance of the result with the sacrificial polymer template. Therefore the ceramic slurry has to be sufficiently fluid to be partially removed under the shearing conditions applied by the rollers or the squeezers, but the remaining ceramic wet coating should be viscous enough to avoid dripping [1], which implies that the processing window is narrow and difficult to fabricate consistently. In contrast, if diatomite is introduced as the starting particle, the remnant diatomite slurry produced during the fabrication of a reticulated porous diatomite does not always block the inter-connected pores, this implies that it need not be completely removed. Unlike common starting particles (e.g., alumina), the inter-connected pores in a diatomite green body were maintained even after uniaxial pressing. Thus, the remnant diatomite particles, which are porous and irregular, do not block all the inter-connected pores. Therefore, reticulated porous diatomite-kaolin composite can be easily prepared using a sacrificial polymer template with higher PPI, such as 80 PPI, owing to the above-mentioned reasons (inherently irregular and porous characteristics of diatomite particles).

From the point of view of possible application fields, the reticulated porous diatomite-kaolin composite can play an important role, as long as the application field does not require excellent mechanical properties. Generally, most ceramics are good electrical insulators. Therefore, one of the main applications of ceramics is as electrical insulators, the ability of withstanding high voltages being an essential requirement for some applications in the field of electrical engineering and solid-state electronics. The author focused on examining the non-load bearing applications of reticulated porous diatomite-kaolin composite such as dielectric barrier or insulator. 


\section{Materials and Methods}

As the sacrificial template, commercial polyurethane foams (SKB Tech, Korea) with 10, 25, 45, 60, and $85 \mathrm{PPI}$, and dimensions of $50 \mathrm{~mm} \times 50 \mathrm{~mm} \times 10 \mathrm{~mm}$ were used for the experiments. A batch of diatomite-kaolin slurry was manufactured to coat the polyurethane foam, which consisted of $100 \mathrm{~g}$ of diatomite (Celite 499, Celite Corp, Lompoc, CA, USA), $30 \mathrm{~g}$ of kaolin (Kaolin, Sigma-Aldrich, Darmstadt, Germany) as a strength enhancer, $250 \mathrm{~mL}$ of distilled water, $4 \mathrm{~g}$ of DARVAN C-N (Vanderbilt Minerals, Norwalk, CT, USA) as a dispersant, and $20 \mathrm{~g}$ of polyvinyl alcohol (PVA) as an organic binder (PVA 500, Junsei Chemical Co., Tokyo, Japan). The mixed diatomite-kaolin slurry was ball-milled using alumina balls for $4 \mathrm{~h}$. The reticulated porous diatomite-kaolin composite specimens were prepared by the replica method. While implementing the conventional replica method, a polyurethane foam specimen was initially soaked in a diatomite-kaolin slurry until its internal pores were saturated with diatomite-kaolin particles. Subsequently, the impregnated polyurethane foam specimen was squeezed to remove any excess diatomite-kaolin slurry, and to enable the formation of a thin diatomite-kaolin coating over the struts of the open-cell pore structure. Then the specimen was dried for $24 \mathrm{~h}$ at room temperature. The dried specimen was heat-treated at $400{ }^{\circ} \mathrm{C}$ for $1 \mathrm{~h}$ to burn off the binder, and subsequently sintered for $1 \mathrm{~h}$ at $1200{ }^{\circ} \mathrm{C}$. After sintering, the material was transformed into reticulated porous diatomite-kaolin composite.

For comparison, reticulated porous alumina specimens were also prepared. Because it was very difficult to compare "the same material and different microstructure" or "different material and the same microstructure". Introducing the diatomite particles to a reticulated porous ceramic, means that the microstructure will be unique which motivated the author to investigate the reticulated porous diatomite. Therefore, the authors compared characteristics the specimens between "a conventional and typical reticulated porous ceramic (alumina) and a novel and unique reticulated porous ceramic (diatomite-kaolin composite)" regardless of the difference of microstructure. Alumina slurry consisted of $130 \mathrm{~g}$ of $\alpha$-alumina (AKP-30, Sumitomo Chemical Co., Ltd., Tokyo, Japan), $100 \mathrm{~mL}$ of distilled water, $1.5 \mathrm{~g}$ of methyl cellulose serving as a thickening agent (Sigma-Aldrich, Darmstadt, Germany), $4 \mathrm{~g}$ of DARVAN C-N (Vanderbilt Minerals, Norwalk, CT, USA) serving as a dispersant, and $5 \mathrm{~g}$ of PVA serving as an organic binder (PVA 500, Junsei Chemical Co., Tokyo, Japan). The optimized alumina slurry composition was obtained only after adding the dispersant in the middle of experiments during this study. Therefore, the un-optimized alumina slurry condition did not include the essential dispersant. All other preparing procedures were the same, except for the sintering temperature, which was $1600{ }^{\circ} \mathrm{C}$.

The pore characteristics of the specimens were characterized using scanning electron microscopy (SEM, JSM-5800, JEOL, Tokyo, Japan) and mercury porosimetry (Autopore IV 9510, Micromeritics, Norcross, GA, USA). The viscosity was measured using a rotational rheometer (Discovery HR-1, TA Instruments, New Castle, DE, USA) at $25^{\circ} \mathrm{C}$. The three-dimensional microstructure was investigated through $\mu$ - computed tomography (CT) (XT H 160, Voxel size $=3 \mu \mathrm{m}$, Nikon, Tokyo, Japan). The compressive strengths of the reticulated porous diatomite specimens were measured with a fixture using an Instron 4206 (Instron, Norwood, MA, USA) testing system. For the compressive strength testing, specimens with dimensions of $20 \mathrm{~mm} \times 20 \mathrm{~mm} \times 20 \mathrm{~mm}$ were prepared. The dielectric breakdown strengths were measured using the standard test apparatus of dielectric breakdown voltage with a DC power supply (C180 30 KV 10 mA, KSC, Seoul, Korea). The authors followed the well-known standard ASTM D149-97a "Standard Test Method for Dielectric Breakdown Voltage and Dielectric Strength of Solid Electrical Insulating Materials at Commercial Power Frequencies" using opposing circular flat plates ( $150 \mathrm{~mm}$ diameter, $10 \mathrm{~mm}$ thickness with edges rounded with a $3 \mathrm{~mm}$ radius) in ambient air at room temperature. Five specimens (with dimensions $150 \mathrm{~mm} \times 150 \mathrm{~mm} \times 10 \mathrm{~mm}$ ) were measured.

\section{Results and Discussions}

Practically and easily obtainable PPI of reticulated porous ceramics is limited to the value of approximately 45 . Therefore, the above-mentioned literatures mostly focused on the study of reticulated 
porous ceramics with less than 45 PPI. For example, reticulated porous alumina ((5 PPI) [31] and (20 PPI) [3,32,33]), reticulated porous alumina-zirconia composite (20 PPI) [34], reticulated porous aluminum nitride (20 PPI) [4], reticulated silicon nitride (10 PPI) [5], reticulated porous silicon carbide ((8 PPI) [6] and (10 PPI) [7]), reticulated porous zirconia (45 PPI) [8], reticulated porous cordierite (10 PPI) [9], reticulated porous yttrium disilicate (60 PPI) [10], and reticulated porous mullite (20 PPI) [11] have been reported.

The detailed reasons are as follows. (1) As the value of PPI increased above approximately 45 PPI, it was difficult for a sacrificial polymer template to completely fill the internal pores with ceramic slurry. It was also very difficult to remove the excessive ceramic slurry while maintaining the formation of thin and uniform ceramic coatings over the strut walls of the sacrificial polymer template. Consequentially, several blocked inter-connected pores were generated by the remnants of excessive ceramic slurry, which should have participated in the ceramic coating on the strut walls of the sacrificial polymer template. It should have been removed completely, but remained even after the squeezing process. It can severely degrade the two main advantages of reticulated porous ceramics: low density and high permeability. (2) When PPI was relatively low, such as 10 or 25 PPI, it was favorable to increase the viscosity of ceramic slurry to coat the strut wall of sacrificial polymer template firmly, minimizing any defects that could be generated by the un-coated strut wall owing to the low adhesiveness, induced by the low viscosity of ceramic slurry, which enhanced the compressive strength of reticulated porous ceramics. However, when PPI approached approximately 45 PPI, a highly viscous ceramic slurry could not easily penetrate and remove the narrow pore channels of the sacrificial polymer template. Therefore, it was difficult to enhance the compressive strength of reticulated porous ceramics by increasing the PPI or viscosity of ceramic slurry.

To demonstrate the difficulty faced during the preparation of reticulated porous ceramic specimen with high PPI, reticulated porous alumina specimens were prepared. Figure 1 shows the compressive strengths of the reticulated porous alumina specimens that were prepared by two different types of alumina slurry compositions, which were sintered at $1600{ }^{\circ} \mathrm{C}$ for $1 \mathrm{~h}$. They had pore densities of 60 and 80 PPI. In Figure 1, the compressive strength of reticulated porous alumina prepared using the optimized alumina slurry, with the well-established composition of binder, solid loading, and dispersant, was higher than that of the reticulated porous alumina prepared using alumina slurry with the un-optimized slurry composition (in which the content is identical, minus the dispersant). Generally, if the viscosity of un-optimized alumina slurry was too high, it could not penetrate the narrow pore channel of the sacrificial polymer template. There were voids inside the reticulated porous alumina and many pore channels of the surface were blocked by the excessive alumina slurry which should have been penetrated the surface instead. If the viscosity of un-optimized alumina slurry was too low, it could not form a firm and defect-free coating layer on the surface of strut walls of the sacrificial polymer template.

To evaluate the coating quality, generally, the applied mass (the amount of coated ceramic slurry after the squeezing process) can be easily measured. However, it is not certain whether the applied mass is properly coated on the strut walls or distributed non-uniformly deep-inside the reticulated porous ceramic specimen. The identification of the coating quality becomes more difficult as the thickness and PPI of the sacrificial polymer template increase owing to the limitation of optical measurement. Therefore, in this study, non-destructive $\mu$-CT analysis was introduced to investigate the prepared reticulated porous ceramic specimens. Figure 2a shows the three-dimensional microstructure of typical reticulated porous alumina specimen, reconstructed by a $\mu$-CT. A representative slice from the $\mu$-CT reconstructions of the specimen is shown in Figure 2b. It is evident that the specimen had a well-defined inter-connected pore structure as intended. However, Figure $2 \mathrm{c}$ shows the three-dimensional microstructure of typical reticulated porous alumina prepared using the un-optimized alumina slurry, reconstructed by a $\mu-\mathrm{CT}$. A representative slice from these $\mu-\mathrm{CT}$ reconstructions is shown in Figure $2 \mathrm{~d}$. Although Figure $2 \mathrm{c}$ does not show any significant difference at a surface level from Figure 2a, in Figure 2d, the voids and non-uniform distribution of strut walls, inside the reticulated porous 
alumina specimen can be observed. The pore channels beneath the surface level were severely blocked, which shows the effect of highly viscous alumina slurry that should have penetrated deep-inside the sacrificial polymer template.

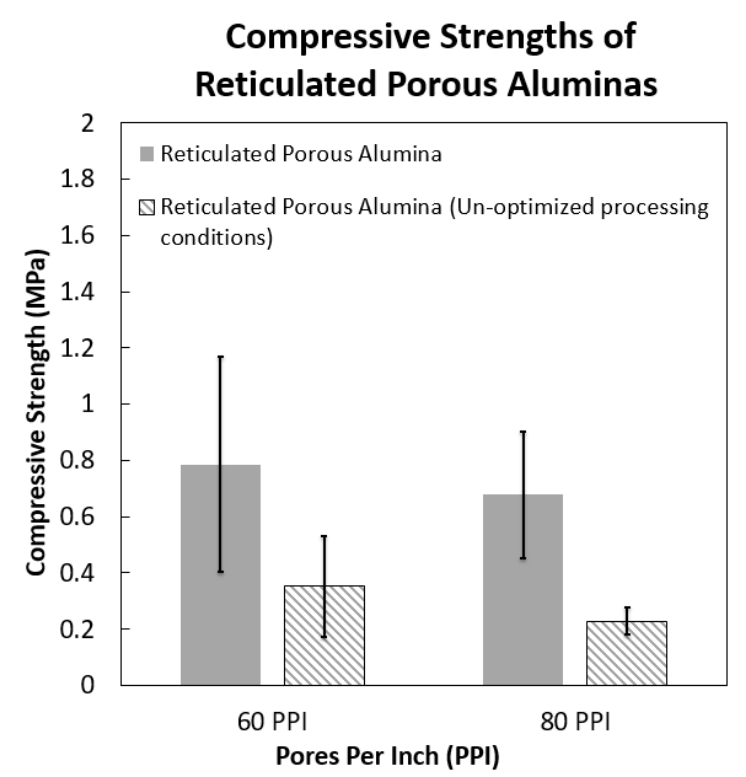

Figure 1. Compressive strengths of the reticulated porous alumina specimens with pore densities of 60 and 80 PPI, which were prepared using the optimized and the un-optimized processing conditions, respectively.

Figure 3a shows the viscosities as a function of the shear rate of the alumina and diatomite-kaolin slurries with optimized slurry compositions at the highest solid loading. On comparing the viscosity of alumina slurry to that of diatomite-kaolin slurry, it was found to be significantly low, implying that it could more easily penetrate the excessively narrow cells of a sacrificial polymer template whose PPI was greater than 60 . This provides a significant advantage of preparing reticulated porous ceramics. Figure $3 \mathrm{~b}$ shows the sacrificial polymer templates (commercial polyurethane foams) with pore densities of 10, 25, 45, 60, and 80 PPI. These polyurethane foams were used as sacrificial polymer templates during the replica method in this study. Figure $3 \mathrm{c}$ shows the as-prepared reticulated porous diatomite-kaolin composite specimens with pore densities of 10, 25, 45, 60, and $80 \mathrm{PPI}$, prepared using the replica method. In previous reports $[21,22,35,36]$, the sintering temperature of the reticulated porous diatomite-kaolin composite was determined to be $1200{ }^{\circ} \mathrm{C}$. The authors already recognized that the reticulated porous diatomite-kaolin composite had similar microstructures up to $1200{ }^{\circ} \mathrm{C}$ because above $1200^{\circ} \mathrm{C}$, a clear coalescence and decrease in the average pore size of diatomite particles began to occur owing to the impurities, such as $\mathrm{Na}_{2} \mathrm{O}, \mathrm{K}_{2} \mathrm{O}, \mathrm{Al}_{2} \mathrm{O}_{3}, \mathrm{CaO}$ and $\mathrm{MgO}$, in the diatomite particles, which easily formed a melt phase in the silica-rich grains [36]. Then, the inherent irregular and porous nature of the diatomite particles diminished. Subsequently, the reason for justification of introducing porous diatomite particles significantly reduced. Definitely, the above-mentioned phenomenon, as described in the literature, was not exactly matched with the reticulated porous diatomite-kaolin composite. However, because diatomite was the main component, the phenomenon corresponding to the sintering temperature was similar to that discussed in the literature. 


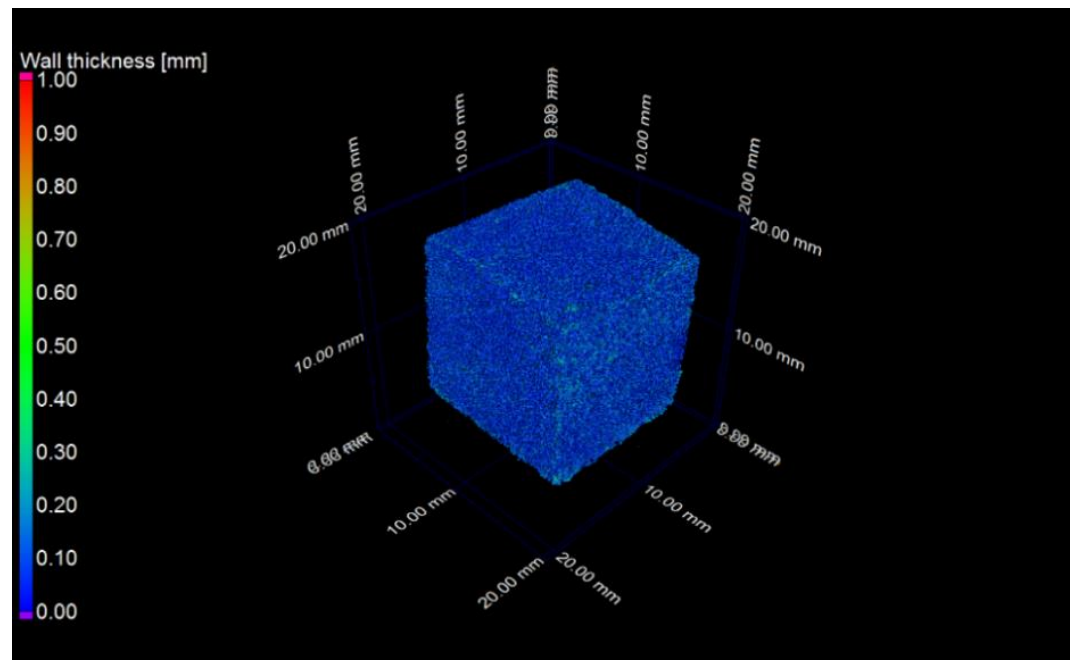

(a)

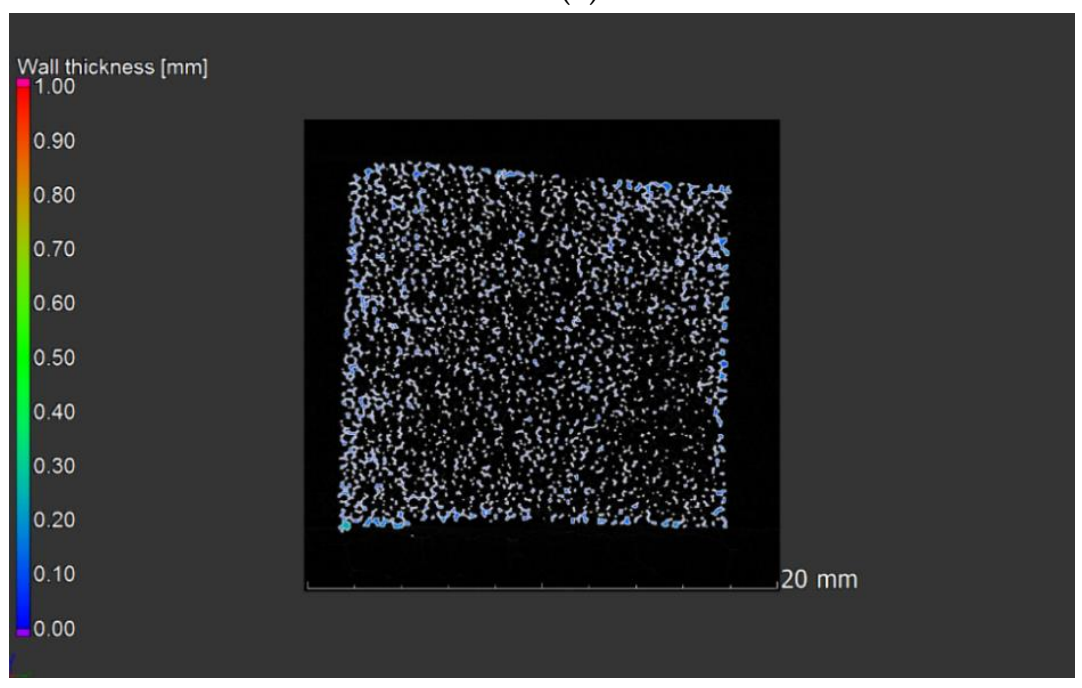

(b)

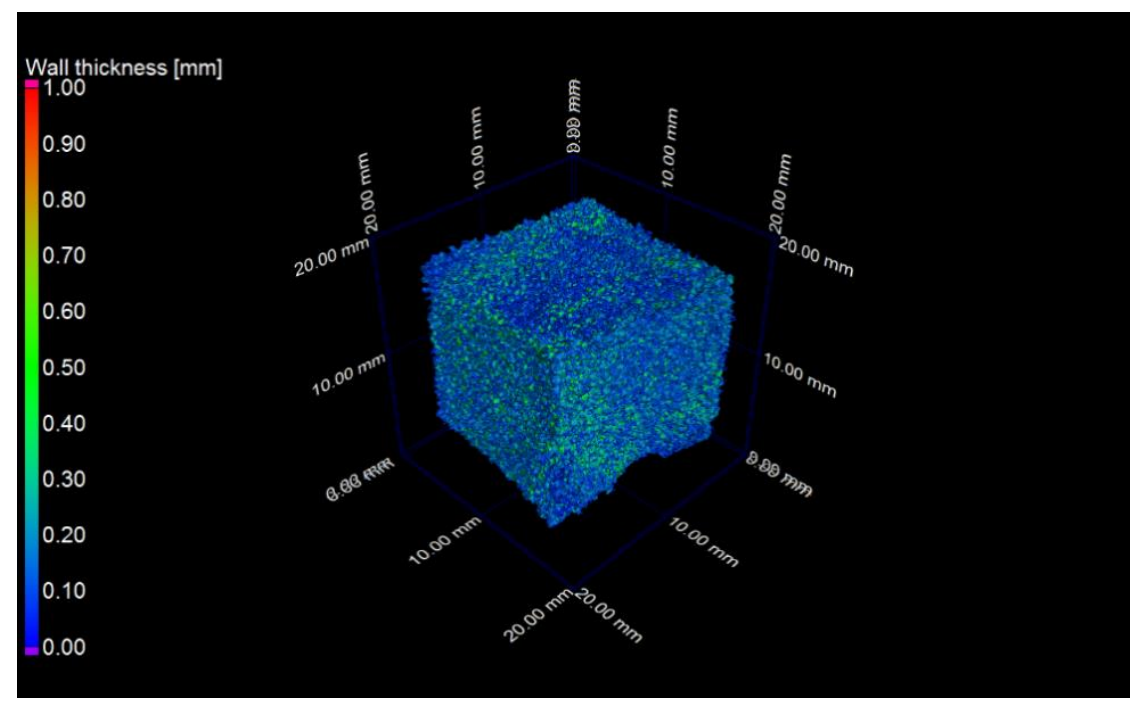

(c)

Figure 2. Cont. 


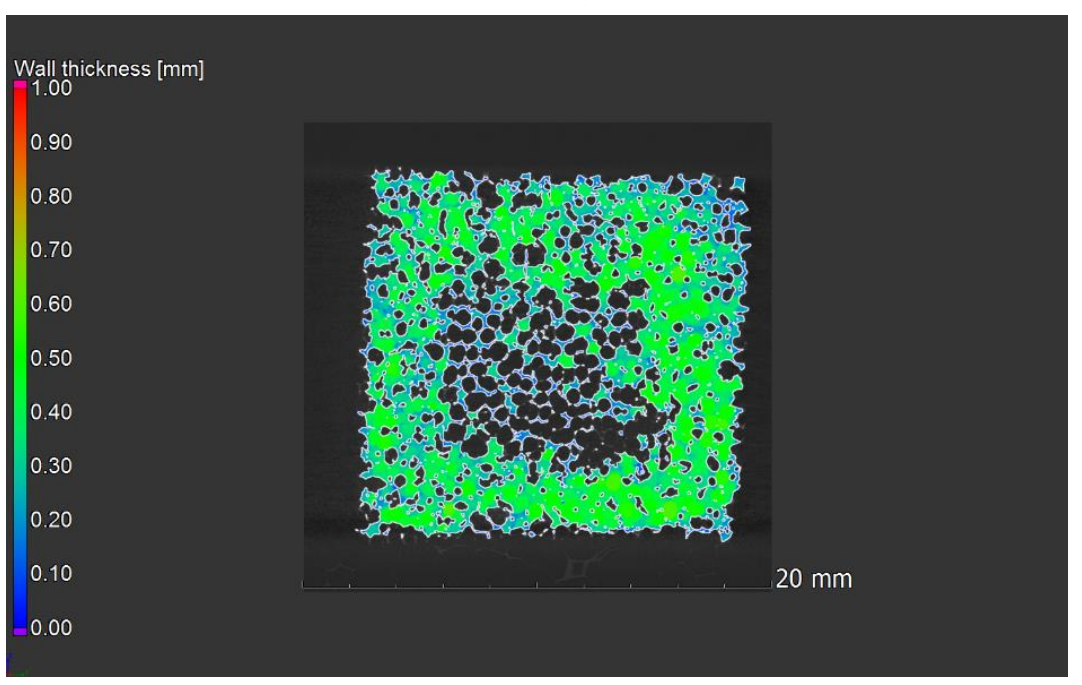

(d)

Figure 2. (a) Three-dimensional microstructure of typical reticulated porous alumina with a pore density of 80 PPI, prepared under optimized slurry conditions, reconstructed by $\mu$-computed tomography (CT). (b) Representative slice taken from the $\mu$-CT reconstructions. (c) Three-dimensional microstructure of typical reticulated porous alumina with a pore density of $80 \mathrm{PPI}$, prepared under un-optimized slurry conditions, reconstructed by $\mu-\mathrm{CT}$. (d) Representative slice taken from the $\mu$-CT reconstructions.

Figure $4 \mathrm{a}, \mathrm{b}$ show the fractured strut walls of a typical reticulated porous alumina specimen and reticulated porous diatomite-kaolin composite specimen, respectively. It is evident that the strut walls of reticulated porous diatomite-kaolin composite were porous unlike those of reticulated porous alumina. Reasonably, the porous nature of the strut walls of reticulated porous diatomite-kaolin composite degraded the compressive strength to a certain degree. This issue will be discussed again in Figure $7 \mathrm{~b}$.

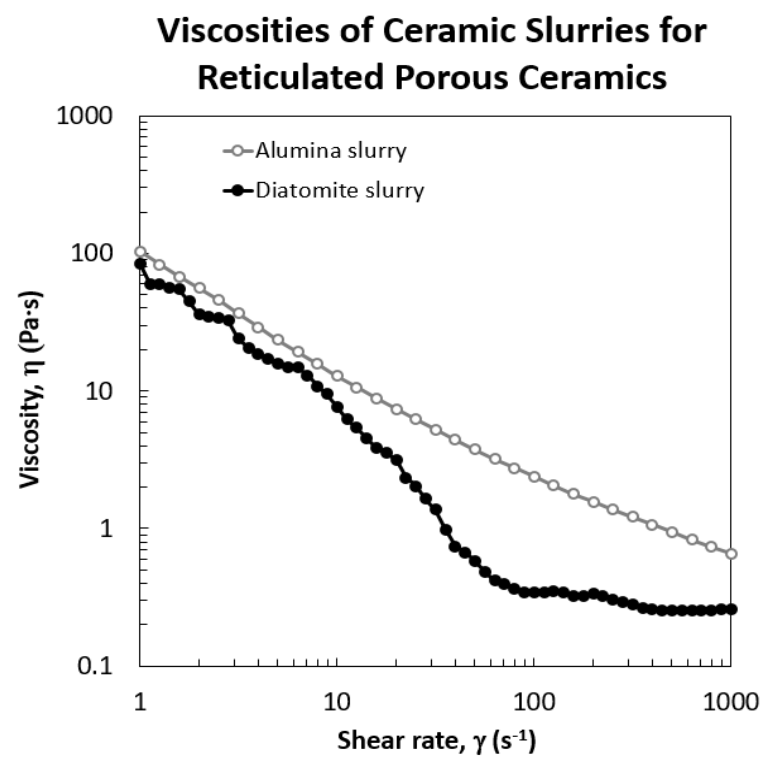

(a)

Figure 3. Cont. 


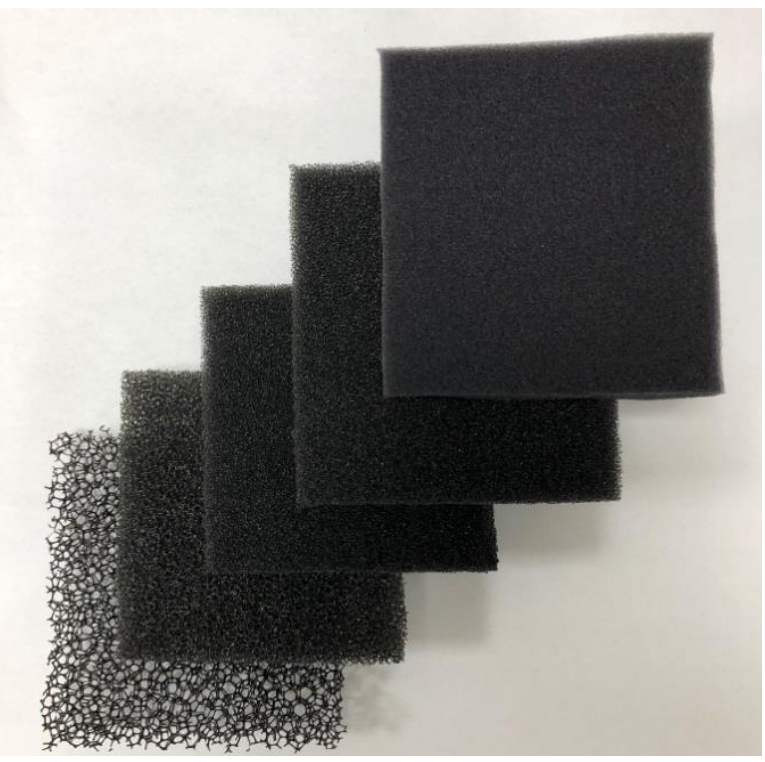

(b)

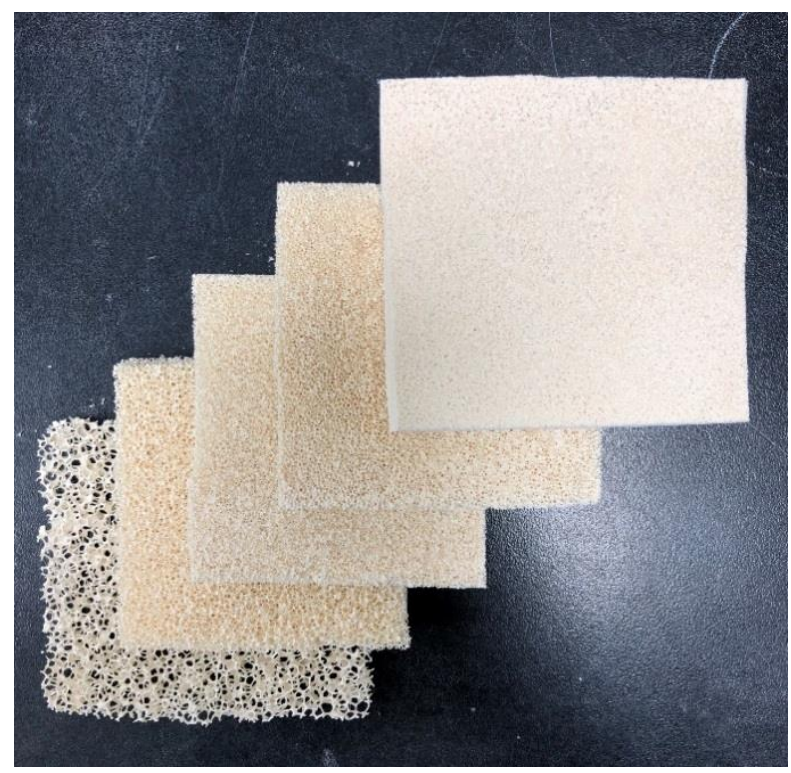

(c)

Figure 3. (a) Viscosities of ceramics slurries for the preparation of reticulated porous alumina and diatomite-kaolin composite. Optical images of (b) sacrificial polymer templates (commercial polyurethane) with pore densities of 10, 25, 45, 60, and $80 \mathrm{PPI}$, which were used as sacrificial polymer templates during the replica method (from left to right). (c) Reticulated porous diatomite-kaolin composite specimens with pore densities of 10, 25, 45, 60, and 80 PPI (from left to right).

To clearly compare the pore structure of the reticulated porous diatomite-kaolin composite with the reticulated porous alumina, Figure 5a shows the three-dimensional microstructure of typical reticulated porous diatomite-kaolin composite prepared using the optimized diatomite-kaolin slurry condition, reconstructed by $\mu-\mathrm{CT}$. A representative slice from the $\mu-\mathrm{CT}$ reconstructions is shown in Figure $5 b$. 


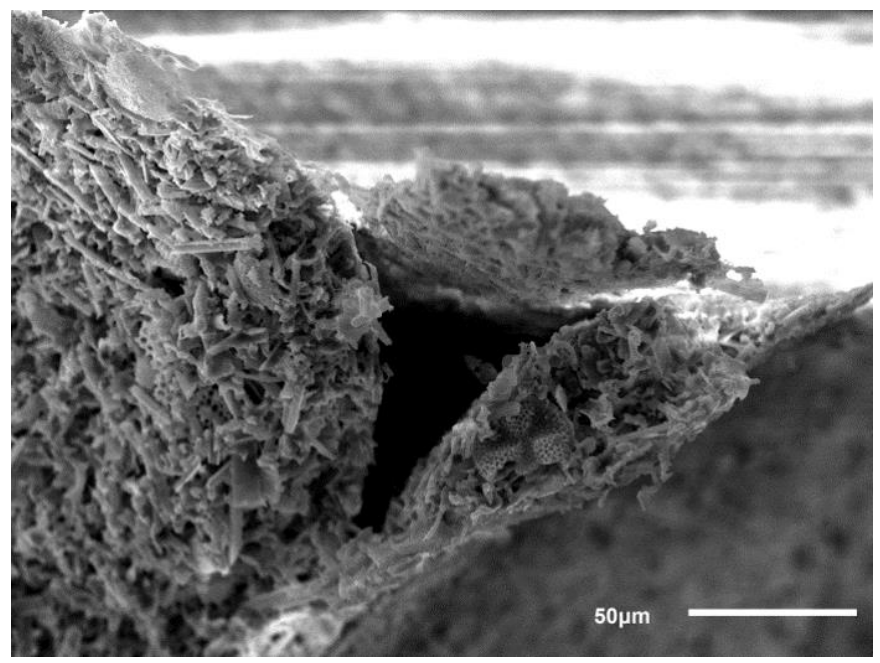

(a)

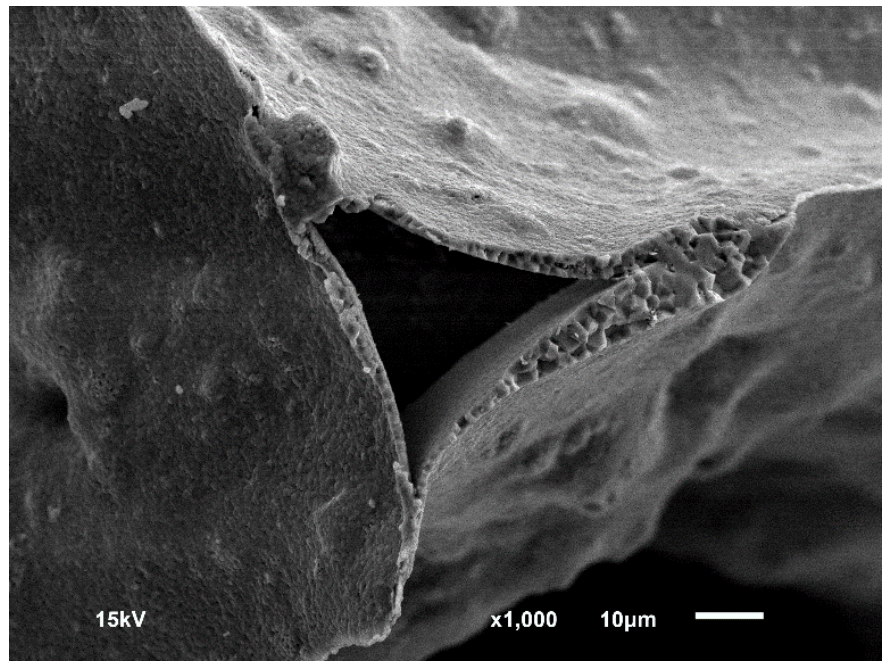

(b)

Figure 4. SEM images of a fractured strut wall of a (a) reticulated porous diatomite-kaolin composite specimen and (b) reticulated porous alumina with a pore density of 10 PPI.

Because the study of the reticulated porous diatomite-kaolin composite is still at its initial stage, the present work focused on determining the suitability of the reticulated porous diatomite-kaolin composite for applications. The conditions of the diatomite-kaolin slurry were optimized for the preparation of the composite, but not for its dielectric properties.

It showed voids and un-uniform distribution of strut walls inside the reticulated porous diatomite-kaolin composite specimen, at an intermediate level between the case of reticulated porous alumina prepared using the optimized alumina slurry condition and un-optimized alumina slurry condition. However, it should be noted that the pore channels beneath the surface level were not severely blocked nor the inter-connectivity was perfect. Interestingly, it is important to note that the success or failure of the preparation of a reticulated porous diatomite-kaolin composite did not depend on the presence of pore channels blocked by redundant diatomite-kaolin particles, which should have been removed in other cases such as the preparation of reticulated porous alumina. This is supported by the pore structure data characterized by mercury porosimeter. 


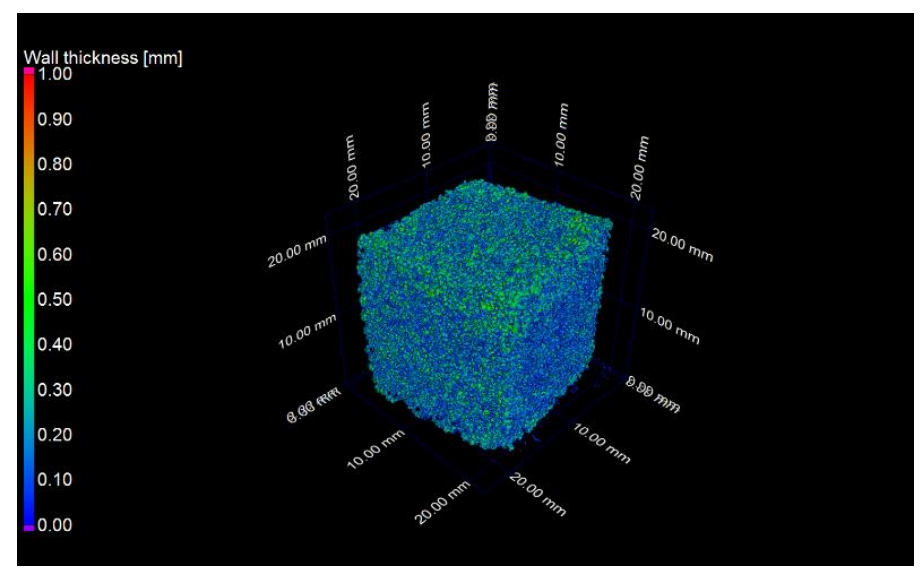

(a)

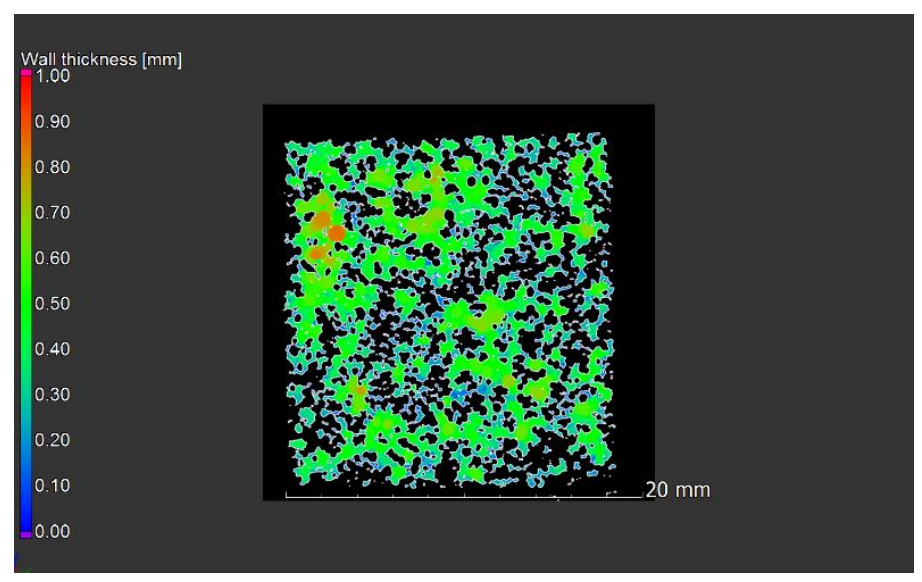

(b)

Figure 5. (a) Three-dimensional microstructure of typical reticulated porous diatomite-kaolin composite with a pore density of $80 \mathrm{PPI}$, prepared under optimized processing conditions, and reconstructed by $\mu-C T$. (b) Representative slice taken from the corresponding $\mu-C T$ reconstructions.

Figure 6a shows the pore size distributions of the reticulated porous diatomite-kaolin composite. As the PPI increased, the pore size and amount of pore volume in the reticulated porous diatomite-kaolin composite slightly increased, because the number of strut walls that were porous and the voids generated by redundant diatomite particles increase accordingly. In Figure 6a, the pore size distribution of individual diatomite particles covered a range from 0.5 to $5 \mu \mathrm{m}$, which included the pore size distribution of the strut walls of reticulated porous diatomite-kaolin composite. This highlights the variability in the pore size. The size of the void generated by the burn-out sacrificial polymer template ranged from 50 to $100 \mu \mathrm{m}$ in Figure 4a, and the large cell composed by the strut walls was in the sub-milimeter range. For comparison, Figure $6 \mathrm{~b}$ shows the pore size distributions of the reticulated porous alumina. Unlike the reticulated porous diatomite-kaolin composite, despite the increasing value of PPI, the pore size and amount of pore volume of the reticulated porous alumina did not significantly increase because the number of dense strut walls does not affect the overall pore size distribution. Additionally, there was little possibility for the generation of voids by the redundant alumina particles, which possibly occurred during the preparation of reticulated porous ceramics with high PPI, accordingly, because the redundant alumina generally blocked the pore channels, as already identified by a representative slice from $\mu$-CT reconstructions of the reticulated porous alumina in Figure 2d. In Figure 6 b, the pores in the strut walls of the reticulated porous alumina were negligible, compared to those of the reticulated porous diatomite-kaolin composite. The alumina particles were well-sintered at $1600{ }^{\circ} \mathrm{C}$, producing dense strut walls. To compare more clearly the porous characteristics of the strut walls of the reticulated porous alumina with those of the reticulated 
porous diatomite-kaolin composite, the pore size distribution focused on the range $0.1 \mu \mathrm{m}$ to $10 \mu \mathrm{m}$. This ensured that the voids generated by the burn-out sacrificial polymer template lay beyond the displayed graph range.

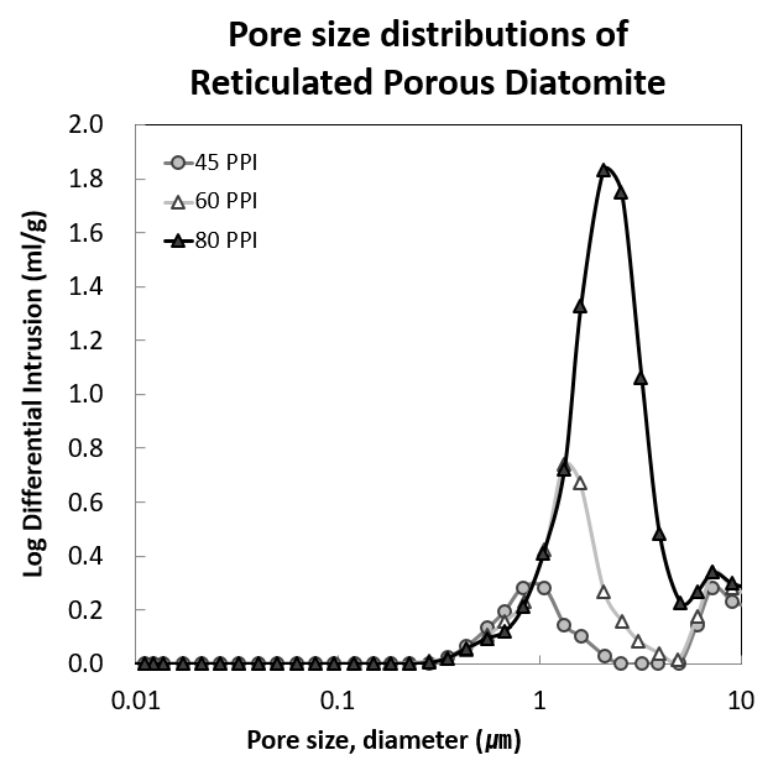

(a)

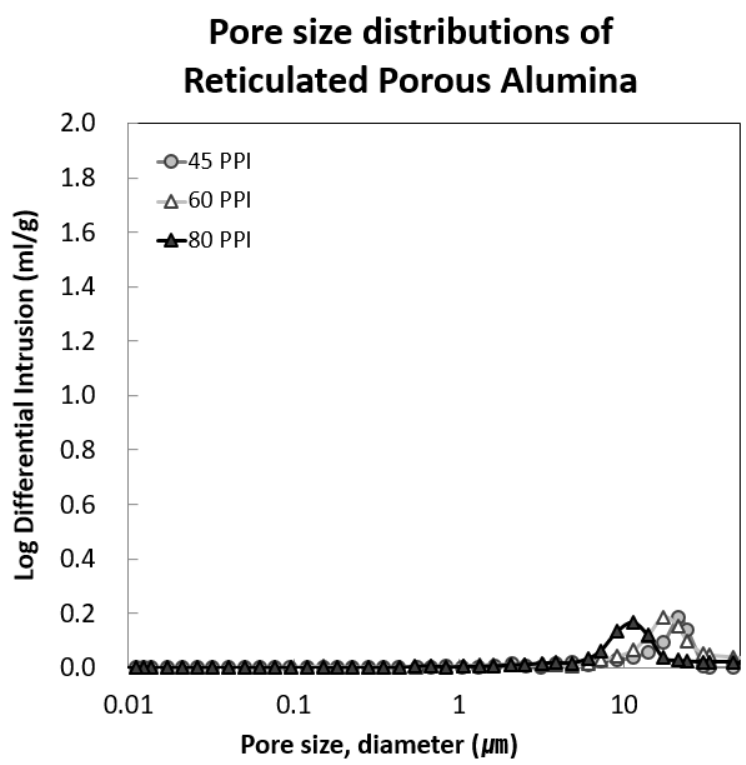

(b)

Figure 6. Pore size distributions of (a) the reticulated porous diatomite-kaolin composite specimens and (b) the reticulated porous alumina specimens, with pore densities of 45,60 , and $80 \mathrm{PPI}$.

Figure $7 \mathrm{~b}$ shows the compressive strengths of the reticulated porous diatomite-kaolin composite sintered at $1200{ }^{\circ} \mathrm{C}$, and reticulated porous alumina specimens sintered at $1600{ }^{\circ} \mathrm{C}$, with pore densities of 60 and $80 \mathrm{PPI}$, respectively. The compressive strength of the reticulated porous diatomite was lower than that of the reticulated porous alumina irrespective of the value of PPI. Considering the presence of porous strut walls in the reticulated porous diatomite-kaolin composite specimen, which can induce an adverse effect on the overall strength, the difference in compressive strengths between the reticulated 
porous diatomite-kaolin composite and reticulated porous alumina was not greater than expected. It should be noted that the flexural strength of the reticulated porous alumina, sintered at $1600{ }^{\circ} \mathrm{C}$ was four times higher than that of the reticulated porous diatomite-kaolin composite, sintered at $1200{ }^{\circ} \mathrm{C}$ [37]. This discrepancy can be explained by the presence of typical void and large defects that were produced when the sacrificial polymer template was burned out, which can overwhelm the overall compressive strength. Relatively, the effect of the presence of porous strut walls in reticulated porous diatomite-kaolin composite was not significant.

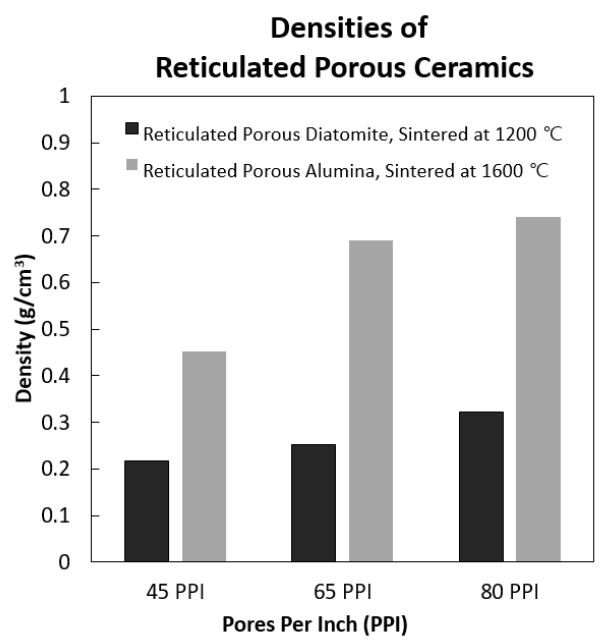

(a)

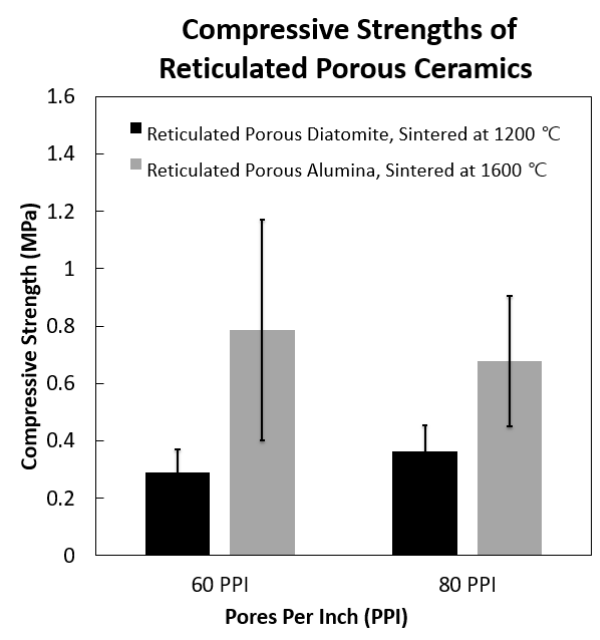

(b)

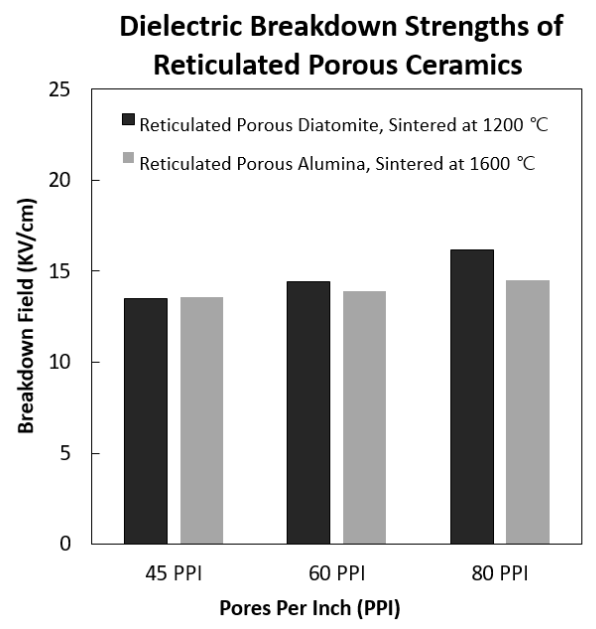

(c)

Figure 7. (a) Densities of reticulated porous diatomite-kaolin composite and reticulated porous alumina specimens, with pore densities of 45,60, and 80 PPI. (b) Compressive strengths of reticulated porous diatomite-kaolin composite and reticulated porous alumina specimens, with pore densities of 60 and 80 PPI. (c) Dielectric breakdown strengths of reticulated porous diatomite-kaolin composite and reticulated porous alumina specimens, with pore densities of 45, 60, and 80 PPI.

The dielectric breakdown strengths of the reticulated porous diatomite-kaolin composite, sintered at $1200{ }^{\circ} \mathrm{C}$, and reticulated porous alumina specimens, sintered at $1600{ }^{\circ} \mathrm{C}$, with pore densities of 45 , 60, and 80 PPI, are shown in Figure 7c. To the best of the authors' knowledge, there are few studies on the dielectric breakdown strength of reticulated porous ceramics. The dielectric breakdown strength of porous ceramics, such as porous alumina (porosity $<30 \%$ ) [38], porous magnesium aluminate (porosity $<20 \%$ ) [39], porous lead zirconate titanate (porosity $<20 \%$ ) [40,41], and porous silica glass (porosity 
$<30 \%$ ) [42], which have low porosity, have been investigated Considering that the porosities of the reticulated porous diatomite-kaolin composite prepared in this study, with pore densities of 45, 60, and $80 \mathrm{PPI}$, were $89.1 \%, 87.4 \%$, and $83.9 \%$, respectively, (in addition, the porosities of the reticulated porous alumina prepared in this study, with pore densities of 45,60 , and 80 PPI, were $88.6 \%, 82.6 \%$, and $81.3 \%$, respectively), the measurements are required to investigate the effect of high porosity on the dielectric breakdown strength. It is evident that the dielectric breakdown strengths of the reticulated porous diatomite-kaolin composite, sintered at $1200^{\circ} \mathrm{C}$, and reticulated porous alumina specimens, sintered at $1600{ }^{\circ} \mathrm{C}$ were approximately $15 \mathrm{KV} / \mathrm{cm}$, which are similar each other, irrespective of the value of PPI. It should be mentioned that the dielectric breakdown strengths of reticulated porous ceramics, with pore densities of 10 and $25 \mathrm{PPI}$, could not be measured owing to the arc-generation induced by the highly inter-connected pores between the electrodes.

Therefore, by compromising the all above-mentioned experimental data, a reticulated porous diatomite-kaolin composite can be act as a potential dielectric barrier, insulating material, or filter, with a low density, good dielectric breakdown strength compared to reticulated porous alumina, and an acceptable mechanical strength, which can be prepared with low processing cost, if it is used under non-hard loading conditions.

\section{Conclusions}

In this study, reticulated porous diatomite-kaolin composite specimens were prepared using a replica method. For comparison, reticulated porous alumina specimens were also prepared. The prepared pore density of the reticulated porous diatomite-kaolin composite was dependent on the pore density of the sacrificial polymer template (in this study, polyurethane foam), namely 10, 25, 45, 60, and 80 PPI.

There are three main advantages of preparing a reticulated porous diatomite-kaolin composite. (1) Because the viscosity of diatomite slurry at the highest solid loading is significantly lower than that of alumina slurry, the preparation of reticulated porous diatomite-kaolin composite is much easier than reticulated porous alumina, especially when the PPI of the sacrificial polymer template is greater than 45. (2) Owing to the inherent porous nature of diatomite particles, there is growing concern about the remnant diatomite particles, during dip-coating and subsequent squeezing process, which may block the pore channels in the confined spaces between the strut walls. (3) Although the compressive strength of a reticulated porous diatomite-kaolin composite is lower than that of a reticulated porous alumina when their PPI values are the same, the dielectric breakdown strengths of reticulated porous diatomite-kaolin composite and reticulated porous alumina are similar, implying that reticulated porous diatomite-kaolin composite can be potentially used under non-hard loading conditions.

These findings indicate the feasibility of using a reticulated porous diatomite-kaolin composite in the application fields that require low cost, less weight, and high permeability, such as a dielectric barrier or insulator.

Author Contributions: J.-H.H. and S.-H.K. conceived and designed the experiments; S.L. performed the experiments; J.L. and J.-H.H. analyzed the data; I.-H.S. contributed reagents/materials/analysis tools; S.L. wrote the paper. All authors have read and agreed to the published version of the manuscript.

Funding: This research was funded by the Fundamental Research Program of the Korea Institute of Materials Science (KIMS) grant number PNK6780, and by the Technology Innovation Program (20003782) of the Ministry of Trade, Industry and Energy.

Acknowledgments: This research was funded by the Fundamental Research Program of the Korea Institute of Materials Science (KIMS) grant number PNK6780, and by the Technology Innovation Program (20003782) of the Ministry of Trade, Industry and Energy.

Conflicts of Interest: The authors declare no conflict of interest. 


\section{References}

1. Studart, A.R.; Gonzenbach, U.T.; Tervoort, E.; Gauckler, L.J. Processing Routes to Macroporous Ceramics: A Review. J. Am. Ceram. Soc. 2006, 89, 1771-1789. [CrossRef]

2. Fey, T.; Betke, U.; Rannabauer, S.; Scheffler, M. Reticulated Replica Ceramic Foams: Processing, Functionalization, and Characterization. Adv. Eng. Mater. 2017, 19. [CrossRef]

3. Rannabauer, S.; Söffker, G.M.; Scheunemann, M.; Betke, U.; Scheffler, M. Increased Mechanical Stability and Thermal Conductivity of Alumina Reticulated Porous Ceramics (RPC) by Nanoparticle Infiltration Processing. Adv. Eng. Mater. 2017, 19. [CrossRef]

4. Betke, U.; Lieb, A.; Scheffler, F.; Scheffler, M. Manufacturing of Reticulated Open-Cellular Aluminum Nitride Ceramic Foams from Aqueous AlN Suspensions. Adv. Eng. Mater. 2016, 19, 1600660. [CrossRef]

5. Yue, H.; Wang, X.; Tian, J. Fabrication of Si3N4 reticulated porous ceramics reinforced by needle-like $\beta$-Si3N4. Ceram. Int. 2014, 40, 8525-8532. [CrossRef]

6. Yao, X.; Tan, S.; Huang, Z.; Jiang, D. Effect of recoating slurry viscosity on the properties of reticulated porous silicon carbide ceramics. Ceram. Int. 2006, 32, 137-142. [CrossRef]

7. Liang, X.; Li, Y.; Sang, S.; Xu, Y.; Chen, Y.; Li, B.; Aneziris, C. Enhanced mechanical properties of SiC reticulated porous ceramics via adjustment of residual stress within the strut. Int. J. Appl. Ceram. Technol. 2018, 15, 28-35. [CrossRef]

8. Jun, I.-K.; Koh, Y.-H.; Song, J.-H.; Lee, S.-H.; Kim, H.-E. Improved compressive strength of reticulated porous zirconia using carbon coated polymeric sponge as novel template. Mater. Lett. 2006, 60, 2507-2510. [CrossRef]

9. Biswas, P.; Varaprasad, K.; Ramavath, P.; Suresh, M.B.; Khanra, A.K.; Johnson, R. Development of Cordierite Based Reticulated Foams with Improved Mechanical Properties for Porous Burner Applications. Trans. Indian Ceram. Soc. 2017, 76, 56-61. [CrossRef]

10. Wu, Z.; Sun, L.; Tian, Z.; Wang, J.; Li, J.; Hu, Z. Preparation and properties of reticulated porous $\gamma-\mathrm{Y}_{2} 2 \mathrm{Si}_{2} \mathrm{O}_{7}$ ceramics with high porosity and relatively high strength. Ceram. Int. 2014, 40, 10013-10020. [CrossRef]

11. Akpinar, S.; Altun, I.A.; Onel, K. Effects of $\mathrm{SiC}$ addition on the structure and properties of reticulated porous mullite ceramics. J. Eur. Ceram. Soc. 2010, 30, 2727-2734. [CrossRef]

12. Touzin, M.; Béclin, F. Fabrication and characterization of composite sol-gel coatings on porous ceramic substrate. J. Eur. Ceram. Soc. 2011, 31, 1661-1667. [CrossRef]

13. Voigt, C.; Aneziris, C.G.; Hubálková, J. Rheological Characterization of Slurries for the Preparation of Alumina Foams via Replica Technique. J. Am. Ceram. Soc. 2015, 98, 1460-1463. [CrossRef]

14. Zhu, X.; Jiang, D.; Tan, S.; Zhang, Z. Improvement in the Strut Thickness of Reticulated Porous Ceramics. J. Am. Ceram. Soc. 2001, 84, 1654-1656. [CrossRef]

15. Pu, X.; Liu, X.; Qiu, F.; Huang, L. Novel method to optimize the structure of reticulated porous ceramics. J. Am. Ceram. Soc. 2004, 87, 1392-1394. [CrossRef]

16. Liang, X.; Li, Y.; Liu, J.; Sang, S.; Chen, Y.; Li, B.; Aneziris, C.G. Improvement of the mechanical properties of $\mathrm{SiC}$ reticulated porous ceramics with optimized three-layered struts for porous media combustion. Ceram. Int. 2017, 43, 3741-3747. [CrossRef]

17. Ha, J.-H.; Lee, S.; Choi, J.R.; Lee, J.; Song, I.-H.; Chung, T.-J. A cobalt-coated reticulated porous alumina for radar-absorption applications. J. Aust. Ceram. Soc. 2019, 55, 883-891. [CrossRef]

18. Ha, J.H.; Oh, E.; Ahmad, R.; Song, I.H. The effects of pore structures on the air permeation properties of sintered diatomite. Ceram. Int. 2013, 39, 3881-3884. [CrossRef]

19. Ha, J.H.; Oh, E.; Song, I.H. The effect of sacrificial templates on the pore characteristics of sintered diatomite membranes. J. Ceram. Soc. Jpn. 2013, 121, 940-945. [CrossRef]

20. Ha, J.H.; Oh, E.; Song, I.H. The use of a diatomite-kaolin composite coating to design the pore characteristics of a sintered diatomite membrane. Ceram. Int. 2014, 40, 2221-2227. [CrossRef]

21. Ha, J.H.; Oh, E.; Song, I.H. The fabrication and characterization of sintered diatomite for potential microfiltration applications. Ceram. Int. 2013, 39, 7641-7648. [CrossRef]

22. Ha, J.H.; Oh, E.; Bae, B.; Song, I.H. The effect of kaolin addition on the characteristics of a sintered diatomite composite support layer for potential microfiltration applications. Ceram. Int. 2013, 39, 8955-8962. [CrossRef]

23. Ha, J.-H.; Lee, J.; Song, I.-H.; Lee, S.-H. The effects of diatomite addition on the pore characteristics of a pyrophyllite support layer. Ceram. Int. 2015, 41, 9542-9548. [CrossRef] 
24. Ha, J.H.; Bae, B.; Song, I.H. Effect of pore characteristics on permeability of sintered diatomite filter for microfiltration. Adv. Appl. Ceram. 2015, 114, 156-163. [CrossRef]

25. Ha, J.H.; Park, Y.H.; Song, I.H. The preparation and pore characteristics of an alumina coating on a diatomite-kaolin composite support layer. J. Ceram. Soc. Jpn. 2014, 122, 714-718. [CrossRef]

26. Ha, J.H.; Jung, D.W.; Song, I.H. The effect of an alumina coating on the pore characteristics of a diatomite-kaolin composite support layer. Ceram. Int. 2014, 40, 12961-12967. [CrossRef]

27. Ha, J.H.; Park, Y.H.; Song, I.H. Alumina coating to realize desired pore characteristics of sintered diatomite membrane. Arch. Metall. Mater. 2015, 60, 1175-1178. [CrossRef]

28. Ha, J.-H.; Lee, S.; Abbas Bukhari, S.Z.; Lee, J.; Song, I.-H. The preparation and characterization of alumina-coated pyrophyllite-diatomite composite support layers. Ceram. Int. 2017, 43, 1536-1542. [CrossRef]

29. Ha, J.H.; Bukhari, S.Z.A.; Lee, J.; Song, I.H.; Lee, S.H. The preparation and characterizations of pyrophyllite-diatomite composite support layers. J. Ceram. Soc. Jpn. 2015, 123, 1043-1050. [CrossRef]

30. Ha, J.H.; Oh, E.; Ahmad, R.; Song, I.H. A particle-stabilized diatomite foam with a bimodal pore structure. J. Ceram. Soc. Jpn. 2013, 121, 426-429. [CrossRef]

31. Banerjee, A.; Bala Chandran, R.; Davidson, J.H. Experimental investigation of a reticulated porous alumina heat exchanger for high temperature gas heat recovery. Appl. Therm. Eng. 2015, 75, 889-895. [CrossRef]

32. Voigt, C.; Zienert, T.; Schubert, P.; Aneziris, C.G.; Hubálková, J. Reticulated porous foam ceramics with different surface chemistries. J. Am. Ceram. Soc. 2014, 97, 2046-2053. [CrossRef]

33. Voigt, C.; Jäckel, E.; Aneziris, C.G.; Hubálková, J. Investigations of reticulated porous alumina foam ceramics based on different coating techniques with the aid of $\mu \mathrm{CT}$ and statistical characteristics. Ceram. Int. 2013, 39, 2415-2422. [CrossRef]

34. Chen, R.; Jia, W.; Wang, Y.; Lao, D.; Hei, D.; Li, S. Optimization of the microstructure and properties of $\mathrm{Al}_{2} \mathrm{O}_{3}-\mathrm{ZrO}_{2}$ reticulated porous ceramics via in-situ synthesis of mullite whiskers and flowing-liquid phase. Mater. Lett. 2019, 243, 66-68. [CrossRef]

35. Van Garderen, N.; Clemens, F.J.; Mezzomo, M.; Bergmann, C.P.; Graule, T. Investigation of clay content and sintering temperature on attrition resistance of highly porous diatomite based material. Appl. Clay Sci. 2011, 52, 115-121. [CrossRef]

36. Akhtar, F.; Rehman, Y.; Bergström, L. A study of the sintering of diatomaceous earth to produce porous ceramic monoliths with bimodal porosity and high strength. Powder Technol. 2010, 201, 253-257. [CrossRef]

37. Ha, J.H.; Bukhari, S.Z.A.; Lee, J.; Song, I.H. Preparation and characterisation of aluminabased composite support layers. Adv. Appl. Ceram. 2016, 115, 229-235. [CrossRef]

38. Biesuz, M.; Luchi, P.; Quaranta, A.; Sglavo, V.M. Theoretical and phenomenological analogies between flash sintering and dielectric breakdown in $\alpha$-alumina. J. Appl. Phys. 2016, 120. [CrossRef]

39. Rupaal, A.S.; Garnier, J.E.; Bates, J.L. Dielectric Breakdown of Porous $\mathrm{MgAl}_{2} \mathrm{O}_{4}$. J. Am. Ceram. Soc. 1981, 64, C100-C101. [CrossRef]

40. Gerson, R.; Marshall, T.C. Dielectric breakdown of porous ceramics. J. Appl. Phys. 1959, 30, 1650-1653. [CrossRef]

41. Zeng, T.; Lou, Q.; Bai, Y.; Dong, X.; Wang, Y. The Dielectric Breakdown Properties of Porous PZT95/5 Ferroelectric Ceramics. Ferroelectrics 2015, 478, 118-126. [CrossRef]

42. Prado, M.O.; Biesuz, M.; Frasnelli, M.; Benedetto, F.E.; Sglavo, V.M. Viscous flow flash sintering of porous silica glass. J. Non-Cryst. Solids 2017, 476, 60-66. [CrossRef]

(C) 2020 by the authors. Licensee MDPI, Basel, Switzerland. This article is an open access article distributed under the terms and conditions of the Creative Commons Attribution (CC BY) license (http://creativecommons.org/licenses/by/4.0/). 